\title{
Inhibition of PI3K increases oxaliplatin sensitivity in cholangiocarcinoma cells
}

\author{
Kawin Leelawat*1,2, Siriluck Narong1, Wandee Udomchaiprasertkul2 ${ }^{2}$, \\ Surang Leelawat ${ }^{3}$ and Sumalee Tungpradubkul ${ }^{4}$
} \author{
Biochemistry, Faculty of Science, Mahidol University, Bangkok, Thailand \\ Email: Kawin Leelawat* - kawin.leelawat@gmail.com; Siriluck Narong - sirilucknarong@hotmail.com; \\ Wandee Udomchaiprasertkul - wandee15@hotmail.com; Surang Leelawat - surangleelawat@gmail.com; \\ Sumalee Tungpradubkul - scstp@mahidol.ac.th \\ * Corresponding author
}

Address: ${ }^{1}$ Department of Surgery, Rajavithi Hospital, Bangkok, Thailand, ${ }^{2}$ Cancer Molecular Therapeutics Unit, Chulabhorn Cancer Center Chulabhorn Research Institute, Bangkok, Thailand, ${ }^{3}$ Faculty of Pharmacy, Rangsit University, Bangkok, Thailand and ${ }^{4}$ Department of

Published: 8 January 2009

Cancer Cell International 2009, 9:3 doi:10.1 186/1475-2867-9-3

This article is available from: http://www.cancerci.com/content/9/I/3

2009 Leelawat et al; licensee BioMed Central Ltd.

This is an Open Access article distributed under the terms of the Creative Commons Attribution License (http://creativecommons.org/licenses/by/2.0), which permits unrestricted use, distribution, and reproduction in any medium, provided the original work is properly cited.
Received: I November 2008

Accepted: 8 January 2009

\begin{abstract}
Background: Resistance of cholangiocarcinoma to chemotherapy is a major problem in cancer treatment. The mechanism of resistance is believed to involve phosphoinositide-3- kinase (PI3K)/ Akt activation. Although the platinum-containing compound oxaliplatin has been extensively used in the treatment of several solid tumors, recent data regarding its use to treat cholangiocarcinoma are ambiguous. Oxaliplatin resistance in this disease could potentially involve PI3K pathways. We, therefore, examined the effects of PI3K pathways in cholangiocarcinoma cells in modulating oxaliplatin resistance.
\end{abstract}

Results: After exposing the cholangiocarcinoma cell lines RMCCAI and KKUI00 to oxaliplatin, the levels of Akt and mTOR phosphorylation increased, as shown by western blot analysis. The WST-I cell proliferation assay showed increased inhibition of cell growth under high concentrations of oxaliplatin. The combination of oxaliplatin with LY294002, an inhibitor of PI3K, resulted in a remarkable arrest of cell proliferation. Deactivation of mTOR by RAD00I was also synergistic with oxaliplatin, although to a lesser extent. The combination of oxaliplatin and a PI3K inhibitor also resulted in a significant induction of apoptosis, as demonstrated by the TUNEL assay.

Conclusion: Activation of PI3K might protect cholangiocarcinoma cells from oxaliplatininduced cytotoxicity. Although the inhibition of PI3K and the inhibition of mTOR both enhance oxaliplatininduced cytotoxicity, PI3K inhibition has a greater effect. Targeting the PI3K pathway may be a useful approach to improve the chemotherapeutic sensitivity of cholangiocarcinoma.

\section{Background}

Cholangiocarcinoma is a cancer characterized by early vascular invasion and metastasis. Patients with cholangiocarcinoma are often diagnosed at advanced stage. Threeyear survival rates of $35 \%$ to $50 \%$ can be achieved only in a subset of patients, who have negative histological margins at the time of surgery [1]. Palliative therapeutic approaches consisting of percutaneous and endoscopic biliary drainage have usually been used for these patients, since there is no effective chemotherapeutic treatment for 
this type of cancer [2]. A novel agent, oxaliplatin, has been extensively used as chemotherapeutic agent in treating solid tumors $[3,4]$. Oxaliplatin is a diaminocyclohexane platinum compound that acts like cisplatin to induce DNA adducts formation. Although early studies suggested that oxaliplatin might be used as an active agent against cholangiocarcinoma $[5,6]$, more recent data indicated that cholangiocarcinoma cells were resistant to oxaliplatin [7]. Therefore, elucidating the mechanism of resistance to oxaliplatin in cholangiocarcinoma cells is crucial to improve the treatment of patients with advanced cholangiocarcinoma.

Activation of the phosphoinositide-3-kinase (PI3K)/Akt signaling pathway is frequently found in cholangiocarcinoma cells [8]. It has been suggested to be a key step leading to the resistance of cancer cells to chemotherapy, especially when using DNA-damaging agents such as cisplatin and oxaliplatin $[9,10]$. Furthermore, previous studies have demonstrated that PI3K/Akt activation regulates sensitivity of cells to G1 arrest induced by mTOR inhibitors [11]. Taken together, these data indicate that chemotherapeutic agents might function better in killing cancer cells if the PI3K pathway is blocked. In this study, we hypothesize that inhibition of PI3K or its downstream target, mTOR, may be increase oxaliplatin efficacy in treating cholangiocarcinoma. The effect of PI3K and mTOR inhibition on oxaliplatin sensitivity of cholangiocarcinoma cells is examined.

\section{Methods}

\section{Cell culture and Materials}

Ham's F12 medium and fetal bovine serum (FBS) were purchased from Gibco (Gibco, Grand Island, NY, USA). Polyclonal antibodies to Akt (phosphorylated at Ser473 and total), mTOR, PP70S6K and P38 MAPK (phosphorylated at Thr180/Tyr182 and total) were purchased from Cell Signaling (Cell Signaling Technology, Beverly, MA, USA). Oxaliplatin was purchased from Sanofi Aventis (Sanofi Aventis, Bridgewater, NJ, USA). Cell culture plastic plates were obtained from Nunc (Thermo Fisher, Rochester, NY, USA). LY294002 (PI3K inhibitor) was purchased from Calbiochem (EMD Chemicals, Gibbstown, NJ, USA). RAD001 (everolimus), an oral derivative of rapamycin, was generously provided by Novartis Pharma AG (Novartis International AG, Basel, Switzerland). Stock solutions $(10 \mathrm{mmol} / \mathrm{L})$ were dissolved in DMSO (SigmaAldrich, St. Louis, MO, USA), stored at $-80^{\circ} \mathrm{C}$, and diluted in fresh medium immediately before use.

The human intrahepatic cholangiocarcinoma cell lines RMCCA1 [12] and KKU100 (kindly provided by Dr. Banchob Sripa, Department of Pathology, Faculty of Medicine, Khon Kaen University) were grown in Ham's F12 medium supplemented with $10 \% \mathrm{FBS}$ at $37^{\circ} \mathrm{C}$ in a $5 \%$
$\mathrm{CO}_{2}$ humidified atmosphere. For experiments, cells were grown in Ham's F12 medium supplemented with 1\% FBS.

\section{Cell proliferation assay}

For proliferation assay, cells were seeded in 96-well culture plastic plates at a density of 10,000 cells per well. Vehicle (PBS) or oxaliplatin in various concentrations (0$200 \mu \mathrm{M}$ ) were added to each well. For the Akt or mTOR inhibition studies, cells were treated with Vehicle (DMSO), LY294002 (PI3K inhibitor) or RAD001 (mTOR inhibitor), respectively, for 1 hour before the addition of oxaliplatin. Cells were then incubated for 48 hours before applying the WST-1 cell proliferation assay reagent (Roche Diagnostics, Laval, Quebec, Canada), according to the recommendation of the manufacturer. The amount of cell proliferation was assessed by determining the $A_{450 \mathrm{~nm}}$ of the cell culture media after addition of WST- 1 for 2 hours. Results were reported as percentage of the inhibition of cell proliferation, where the optical density measured from vehicle-treated cells was considered to be $100 \%$ of proliferation. Percentage of inhibition of cell proliferation was calculated as follows: $\left(1-A_{\operatorname{exp~group}} / A_{\text {control }}\right) \times 100$.

\section{Cell apoptosis assay}

The number of apoptotic cells was determined with the Apo-BrdU TUNEL assay kit (Invitrogen, Carlsbad, CA, USA), following manufacturer's instructions. Briefly, cells were washed with cold PBS and then fixed with $1 \%$ paraformaldehyde and ice-cold $70 \%$ ethanol for 30 minutes. Fixed cells were labeled with BrdUTP using terminal deoxynucleotide transferase (TdT) at $37^{\circ} \mathrm{C}$ for 60 minutes and stained with Alexa Fluor 488-labeled anti-BrdU antibody for 30 minutes at room temperature. To score for apoptosis, cells were counterstained with DAPI, and at least 200 cells were counted under fluorescent microscope at $400 \times$ magnification. The percentage of apoptotic cells per experimental condition was then determined.

\section{Western blotting analyses}

Approximately 500,000 cells were seeded in a six-well culture plate, followed by treatment with vehicle (PBS), or oxaliplatin for 12 hours. Cells were collected, washed with PBS and lysed in lysis buffer. Western blot analyses were performed as previously described [8]. The blots were first probed with antibodies against phospho-Akt, phosphomTOR, phospho-P70S6K or cleaved caspase- 3 and then reprobed with antibodies against total Akt, mTOR, P70S6K or caspase-3. Bound antibodies were detected using chemiluminescence.

\section{Statistical analysis}

The experiments were all performed in triplicate, and each result is reported as the mean with SD. Data between three or more groups were compared using the one-way analysis of variance, followed by Dunnett's post hoc test. A p- 
value of less than 0.05 was considered statistically significant.

\section{Results \\ Oxaliplatin slightly inhibits cholangiocarcinoma cell proliferation}

Cholangiocarcinoma cells were treated with $0-200 \mu \mathrm{M}$ oxaliplatin for 48 hours, and then a cell proliferation assay was performed using WST-1. The percentage of cell proliferation inhibition was set at $0 \%$ when the cells were treated with vehicle (PBS). Both RMCCA1 and KKU100 displayed a slight dose-sensitivity to oxaliplatin. For RMCCA1, the inhibition of cell proliferation was $14.0 \% \pm$ 6.54 and $28.7 \% \pm 7.33$ in cells treated with 100 and 200 $\mu \mathrm{M}$ of oxaliplatin, respectively. For KKU100, the inhibi- tion of cell proliferation was $8.1 \% \pm 3.31$ and $15.6 \% \pm$ 3.30 in cells treated with 100 and $200 \mu \mathrm{M}$ of oxaliplatin, respectively (Figs. 1A and $1 \mathrm{~B}$ ).

\section{Phosphorylation of Akt and mTOR was induced by oxaliplatin in cholangiocarcinoma cells}

Previous studies demonstrated that activation of PI3K pathway induced chemoresistance in cancer cells. To assess PI3K activation in cholangiocarcinoma cells after treatment with oxaliplatin, the levels of phosphorylated Akt and mTOR, two downstream signal transduction molecules in the PI3K pathway, were examined. Cholangiocarcinoma cells were treated with $0-200 \mu \mathrm{M}$ of oxaliplatin for 12 hours or treated with $100 \mu \mathrm{M}$ of oxaliplatin for 0-48 hours. Cells were then subjected to west-
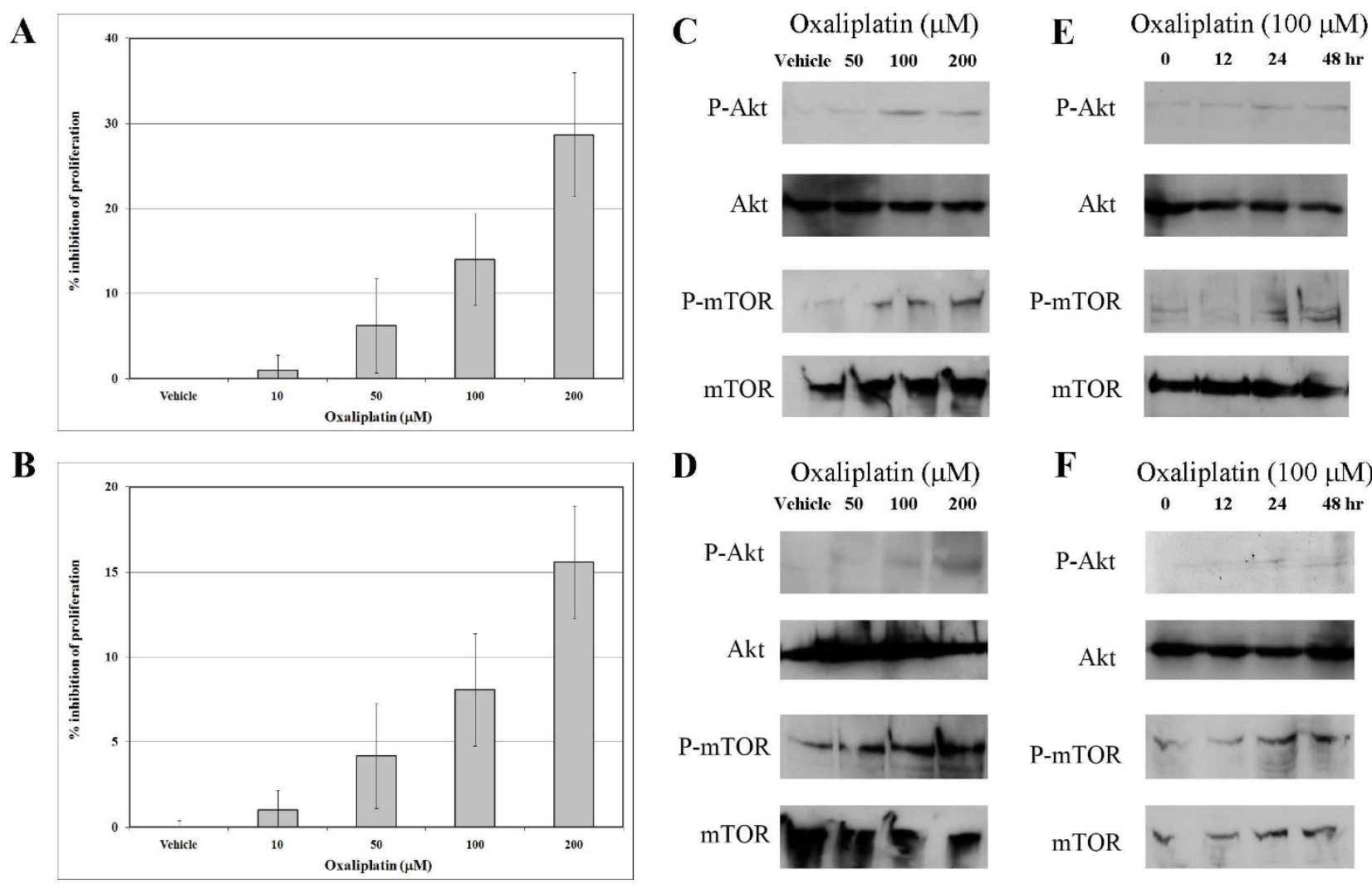

D

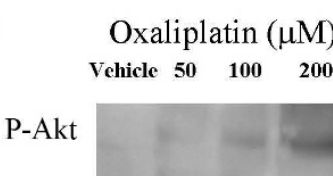

Akt

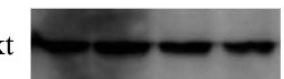

P-mTOR mTOR
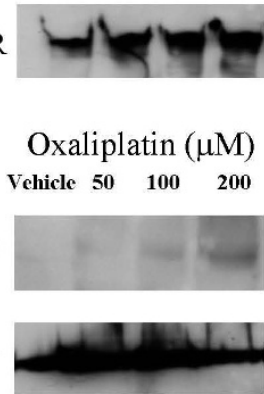

P-mTOR

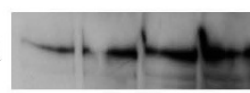

mTOR

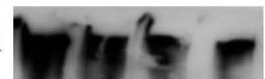

F

Oxaliplatin $(100 \mu \mathrm{M})$ $\begin{array}{llll}0 & 12 & 24 & 48 \\ \mathrm{hr}\end{array}$

P-Akt

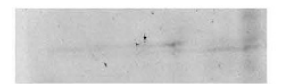

Akt

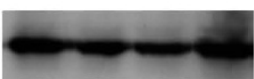

P-mTOR

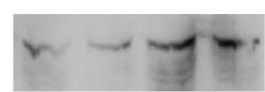

mTOR

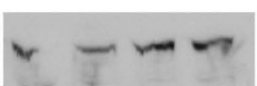

Figure I

Effect of oxaliplatin on cholangiocarcinoma cells. (A) RMCCAI and (B) KKUI00 cells were treated with oxaliplatin at various concentrations $(0,10,50,100$ and $200 \mu \mathrm{M})$ for 48 hours. Effect on cell proliferation was measured by WST-I and analyzed by spectrophotometric analysis (Absorbance $=450 \mathrm{~nm}$ ). Results are reported as percentage inhibition of cell proliferation, where the optical density value from vehicle-treated cells was set as $100 \%$ of proliferation. Results are represented by the mean \pm SE of three independent experiments. Phosphorylation of Akt and mTOR in (C) RMCCAI and (D) KKUI00 cells following 0-200 $\mu \mathrm{M}$ oxaliplatin treatment for $12 \mathrm{~h}$ and phosphorylation of Akt and mTOR in (E) RMCCAI and (F) KKUI00 cells following $100 \mu \mathrm{M}$ oxaliplatin treatments for $0-48 \mathrm{~h}$ were determined by western blotting. Total Akt and mTOR were used as loading control. Representatives of the three independent experiments are shown. 
ern blot analysis. The levels of Akt and mTOR phosphorylation increased as the concentration of oxaliplatin increased (Figs. 1C and 1D). In addition, the increase in the levels of phosphorylated Akt and mTOR is observed as early as 12 hours and as late as 48 hours after oxaliplatin treatment in both cell lines (Figs. 1E and 1F). This result is in agreement with that from a previous study, indicating that the mechanism of cell protection to chemotherapeutic agent is through the activation of the PI3K pathway $[9,12]$.

\section{Inhibition of PI3K and $m$ TOR increases the cytotoxicity of oxaliplatin in cholangiocarcinoma cell lines}

To evaluate the effect of the PI3K pathway on oxaliplatin resistance, cholangiocarcinoma cells were treated with specific inhibitors of PI3K (LY294002) and mTOR (RAD001), with or without oxaliplatin. Western blot analysis was used to determine the levels of phosphorylation of Akt and P70S6K, the downstream targets of PI3K and mTOR, respectively. Cell growth was determined by the cell proliferation assay. When treated with LY294002, the cells clearly exhibit lower levels of Akt and P70S6K phosphorylation compared to what is seen under control conditions. RAD001 also significantly reduced the phosphorylation of P70S6K, but it increased the phosphorylation of Akt (Figs. 2A and 2B).

Oxaliplatin-induced resistance of cells was shown to be modulated by inhibitors of either Akt or mTOR. Cholangiocarcinoma cells were pretreated with either $10 \mu \mathrm{M}$ LY294002 or $0.5 \mu \mathrm{M}$ RAD001 for 1 hour, followed by incubation with $0-200 \mu \mathrm{M}$ oxaliplatin. Pretreatment with LY294002 resulted in a two-fold increase in the percentage of inhibition of cell proliferation at both 100 and 200 $\mu \mathrm{M}$ of oxaliplatin when compared to the control (RMCCA1; from $14.1 \% \pm 3.76$ to $35.1 \% \pm 5.14$ at $100 \mu \mathrm{M}$ oxaliplatin; $p=0.002$ and from $28.6 \% \pm 7.25$ to $57.4 \% \pm$ 7.19 at $200 \mu \mathrm{M}$ oxaliplatin; $p=0.004$ and KKU100; from $8.1 \% \pm 2.33$ to $20.7 \% \pm 1.98$ at $100 \mu \mathrm{M}$ oxaliplatin; $p=$ 0.09 and from $15.5 \% \pm 4.02$ to $30.7 \% \pm 5.10$ at $200 \mu \mathrm{M}$ oxaliplatin; $p=0.01$, (Figs. $2 \mathrm{C}$ and 2D). Pretreatment with RAD001 resulted in increased inhibition of cell proliferation only at high concentrations of oxaliplatin (RMCCA1; from $14.1 \% \pm 3.76$ to $20.5 \% \pm 4.37$ at $100 \mu \mathrm{M}$ oxaliplatin; $p=0.2$ and from $28.7 \% \pm 7.25$ to $45.3 \% \pm 6.20$ at $200 \mu \mathrm{M}$ oxaliplatin; $p=0.04$ and KKU100; from $8.1 \% \pm 2.33$ to $12.6 \% \pm 2.54$ at $100 \mu \mathrm{M}$ oxaliplatin; $p=0.20$ and from $15.5 \% \pm 4.02$ to $22.0 \% \pm 2.58$ at $200 \mu \mathrm{M}$ oxaliplatin; $p=$ $0.006)$. The significant increase of oxaliplatin-induced cytotoxicity in cholangiocarcinoma cells upon pretreatment with specific kinase inhibitors indicates that resistance of cholangiocarcinoma cells to chemotherapeutic agents can be modulated.

\section{LY294002 increases oxaliplatin-induced cell apoptosis}

In order to determine the mechanism by which LY294002 and RAD001 increase oxaliplatin-induced cytotoxicity, TUNEL apoptosis assays were performed. $10 \mu \mathrm{M}$ LY294002, $0.5 \mu \mathrm{M}$ RAD001 or control vehicle (DMSO) were added to RMCCA1 cholangiocarcinoma cells, followed by treatment of the cells with $0-200 \mu \mathrm{M}$ oxaliplatin for 48 hours. Exposure to either LY294002 or RAD001 alone did not significantly alter the number of RMCCA1 apoptotic cells when compared to the control. However, the combination of LY294002 with 100-200 $\mu \mathrm{M}$ oxaliplatin significantly increased the number of apoptotic cells (from $21.8 \% \pm 7.33$ to $45.6 \% \pm 6.13$ at $100 \mu \mathrm{M}$ oxaliplatin; $p=0.008$ and from $34.5 \% \pm 6.72$ to $62.4 \% \pm 6.68$ at $200 \mu \mathrm{M}$ oxaliplatin; $p=0.004)$. In contrast, the combination of RAD001 with 100-200 $\mu \mathrm{M}$ oxaliplatin did not significantly increase the number of apoptotic cells (Figs. 3A and $3 \mathrm{~B})$.

To verify that apoptosis was the direct cause of cell death, the presence of cleaved caspase-3, a central marker of apoptosis, was determined by western blot analysis. As shown in Fig. 3C, the level of cleaved caspase-3 was very low in cholangiocarcinoma cells treated with $10 \mu \mathrm{M}$ of LY294002, $0.5 \mu \mathrm{M}$ of RAD001 or oxaliplatin alone. On the other hand, the level of cleaved caspase-3 was increased in cholangiocarcinoma cells treated with LY294002 in combination with 100 or $200 \mu \mathrm{M}$ of oxaliplatin.

\section{Discussion}

Cholangiocarcinoma is a rapidly lethal disease and generally considered to be incurable. One of the main reasons for its low survival rate is that cholangiocarcinoma exhibits extensive local invasion and frequent regional lymph node metastasis. Most patients are not candidates for curative surgical resection [13]. Until recently, there has been no effective chemotherapeutic drug for this disease.

Oxaliplatin has been used for the treatment of a number of solid tumors including lung, gastric, and colorectal cancer $[[3,6]$, and [14]]. Recently, a prospective multicenter phase II study focused on capecitabine and oxaliplatin (CAPOX) combination therapy in advanced cholangiocarcinoma [3,7]. Unfortunately, the results suggested that this regimen produced poor results for intrahepatic cholangiocarcinoma [7]. An alternative strategy is then needed to evaluate the efficacy of oxaliplatin as chemotherapeutic agent. We used two cholangiocarcinoma cell lines, RMCCA1 and KKU100, derived from cholangiocarcinoma patients to study the effect of oxaliplatin in vitro. These cell lines exhibited resistance to oxaliplatin, even at high concentrations (100-200 $\mu \mathrm{M})$. In addition, we dem- 


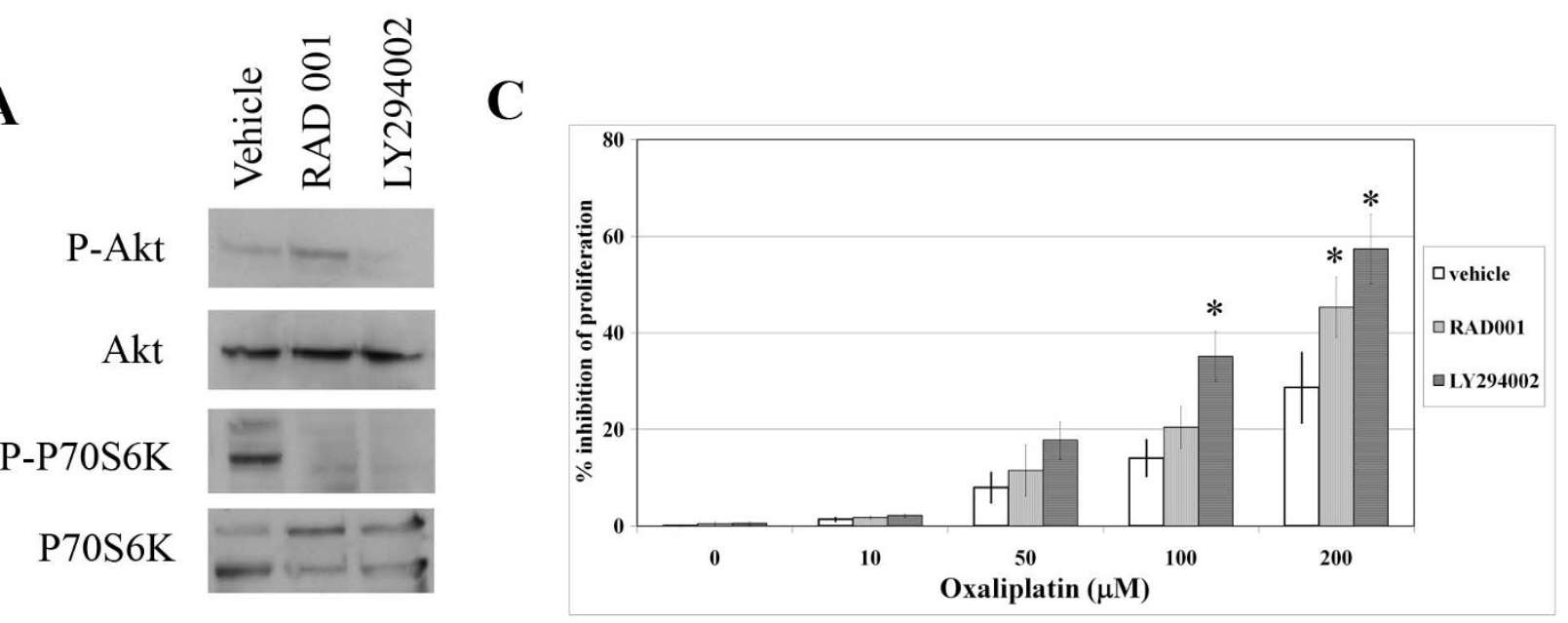

\section{B}

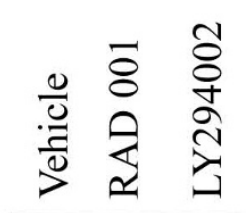

\section{D}

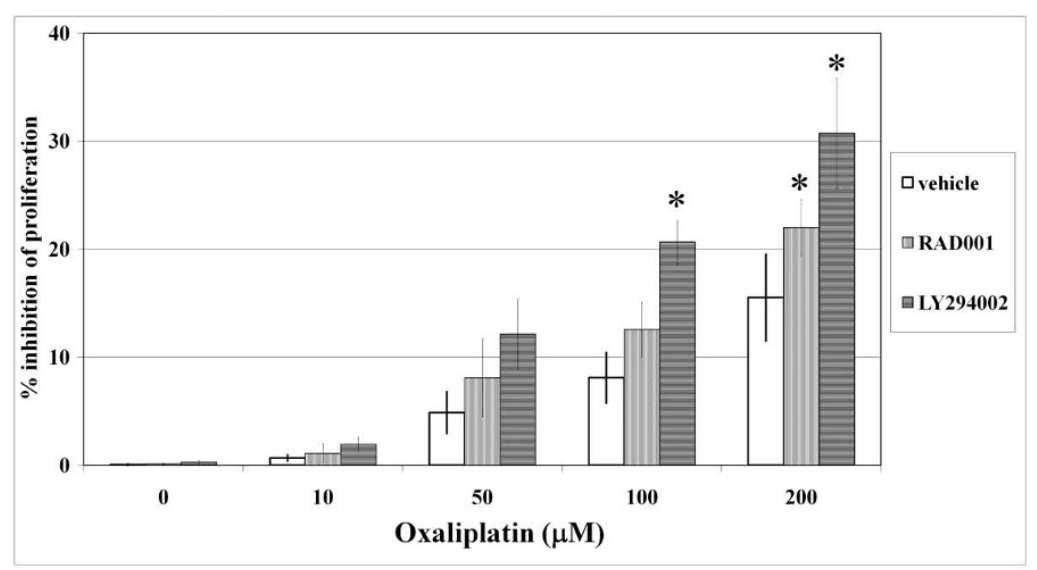

\section{Figure 2}

Inhibition of Akt and $m$ TOR increases the oxaliplatin-induced cytotoxicity in cholangiocarcinoma cell lines. The effects of Akt (LY294002), and mTOR (RAD00I) inhibitors on the phosphorylation of Akt and P70S6K in (A) RMCCAI and (B) KKUI00 cells were determined by western blotting. Total Akt and P70S6K were used as loading controls. Cells were treated with $10 \mu \mathrm{M}$ LY294002, $0.5 \mu \mathrm{M}$ RAD00 I or control vehicle (DMSO) for 24 hours. Representatives from 3 independent experiments are shown. The effects of LY294002 and RAD00I in (C) RMCCAI and (D) KKUI00 cells following treatment with or without oxaliplatin are shown. Cells were treated with I0 $\mu$ M LY294002, $0.5 \mu$ M RAD00I or control vehicle (DMSO), followed by the addition of $0-200 \mu \mathrm{M}$ oxaliplatin for 48 hours. Cell proliferation was measured by WST-I and analyzed by spectrophotometric analysis (Absorbance $=450 \mathrm{~nm}$ ). Results are reported as a percentage inhibition of cell proliferation, where the optical density value from vehicle-treated cells were set as $100 \%$ of proliferation and represent the mean \pm SE of three independent experiments. $\left(^{*}, p<0.05\right.$ versus the same concentration of oxaliplatin)

onstrated that oxaliplatin-treated cholangiocarcinoma cells exhibit high levels of Akt and mTOR phosphorylation as a result of PI3K activation. Thus, we hypothesized that activation of the PI3K pathway in cholangiocarcinoma cells may, in turn, protect the cells from oxaliplatininduced cytotoxicity. Our results indeed showed that inhibition of Akt by LY294002 significantly increased oxaliplatin efficacy in inhibiting cell proliferation. This finding suggests that Akt phosphorylation might be attributed to oxaliplatin resistance in cholangiocarcinoma cells.
This result is also consistent with recent evidence showing that the mechanism of drug resistance in cancer cells was primarily through the induction of PI3K/Akt pathways [15].

Previous studies demonstrated that exposure of cancer cells to oxaliplatin induced protein misfolding. These misfolded proteins are prone to oxidative stress as a result of better accessibility of reactive oxygen species (ROS) to the protein structure [16]. As a consequence, recruitment of 
A

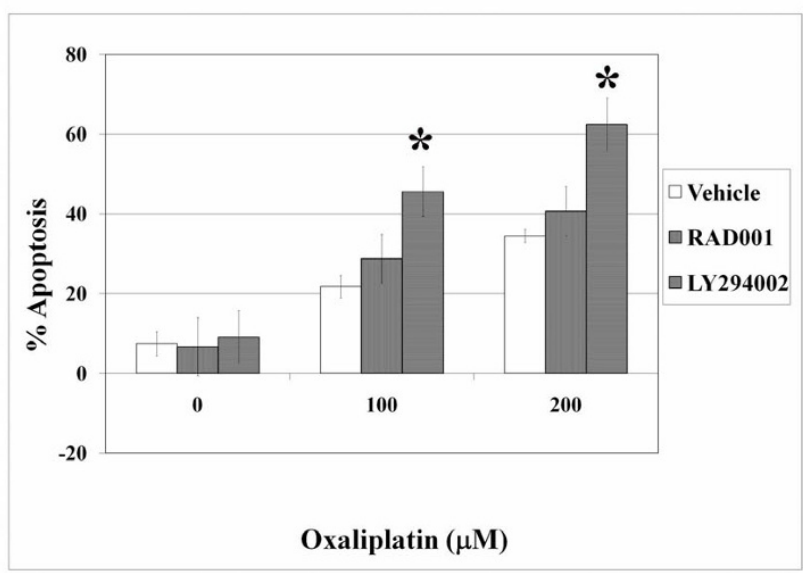

B
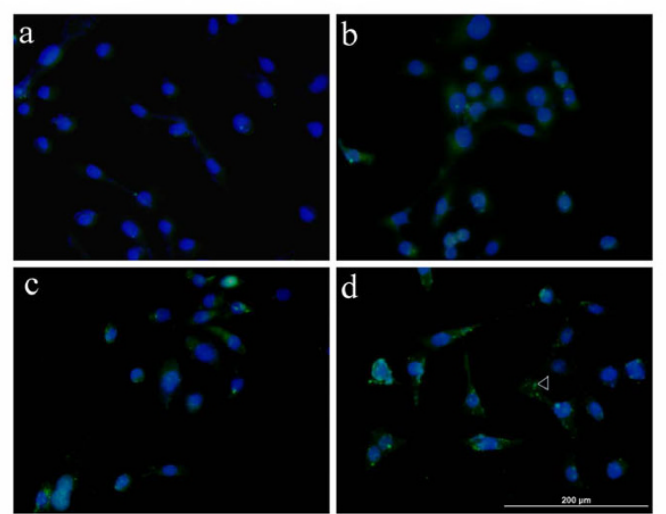

C

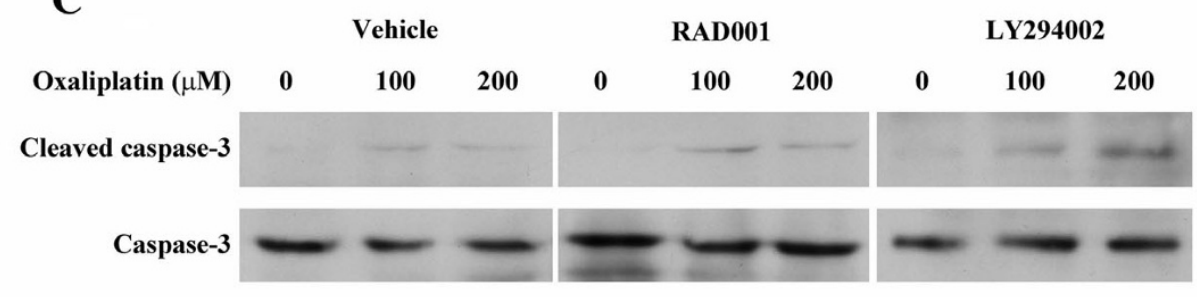

Figure 3

LY294002 modulated oxaliplatin-induced cell apoptosis. (A) Cells were added with I0 $\mu$ M LY294002, $0.5 \mu$ M RAD00 I or control vehicle and then treated with 0-200 $\mu$ M oxaliplatin. TUNEL assay was done as described in the Methods section. The percentage of apoptotic cells in each group of treatments was demonstrated (values shown as mean \pm SD, $* ; p<0.05$ versus the same concentration of oxaliplatin). (B) Apoptotic cells (green spots) were detected with an ApopTag Staining kit and counterstained with DAPI (blue). RMCCAI cells were treated with Vehicle (a) and I00 $\mu$ M oxaliplatin (b). Cells were treated with RAD00I plus $100 \mu$ M oxaliplatin (c) and with LY294002 plus $100 \mu$ M oxaliplatin (d) (Arrow head indicates the apoptotic cells). (C) Western blots analysis of cleaved caspase- 3 and caspase- 3 in each group of treatments. The blots were representative of three independent experiments.

Bax to the mitochondria, release of cytochrome $\mathrm{c}$ to the cytosol, activation of caspase-3 and apoptotic cell death take place in cancer cells treated with oxaliplatin. Recently, Kim et al. reported that the activation of Akt could inhibit oxaliplatininduced apoptosis through maintaining XIAP protein levels [10]. In this study, we demonstrate that inhibition of Akt by LY294002 increases the percentage of apoptotic cells after oxaliplatin treatment. In addition, activation of caspase-3 was clearly observed in cholangiocarcinoma cells treated with both LY294002 and oxaliplatin. These data indicate that activation of Akt in cholangiocarcinoma cells may be the key mechanism in inhibiting oxaliplatin-induced apoptosis.

PI3K and Akt regulate the processes of cellular glucose metabolism. Inactivation of PI3K and Akt may have deleterious effects on normal cell metabolism [17]. Therefore, only inhibitors of those downstream molecules of PI3K and Akt that are not involved in glucose metabolism should be considered for clinical treatment. The mammalian target of rapamycin is mTOR, a $289 \mathrm{kDa}$ serine/threonine kinase. mTOR is a downstream effector of the PI3K/ Akt signaling pathway involved in the regulation of many transduction processes of cell growth as well as cell cycle progression, membrane trafficking, protein degradation, and protein kinase $\mathrm{C}$ signaling and transcription [18].

Recently, a derivative of rapamycin, RAD001 (everolimus), has been developed. RAD001 has been shown to inhibit mTOR activity, thereby halting the proliferation of cancer cells, both in vitro and in vivo. Phase II clinical trials with RAD001 are currently being performed for many types of cancers $[18,19]$. Based on the results of our study, the $0.5 \mu \mathrm{M}$ RAD001 alone did not inhibit the proliferation of cholangiocarcinoma cells. This is consistent with a previous study, which demonstrated that RAD001 has only cytostatic effects in cancer cells. To induce cytotoxicity of RAD0001 in cancer cells, other 
chemotherapeutic drugs should be combined with RAD0001 $[18,20]$. For example, pretreating ovarian cancer cells with RAD001 can increase their sensitivity to cisplatin [21]. In this study, we found that RMCCA1 and KKU100 displayed high levels of Akt and mTOR phosphorylation after treatment with oxaliplatin. Pretreatment of cholangiocarcinoma cells with $0.5 \mu \mathrm{M}$ RAD001 significantly increased the sensitivity of oxaliplatin when used at $200 \mu \mathrm{M}$. However, pretreatment with $0.5 \mu \mathrm{M}$ RAD001 did not significantly increase the efficacy of oxaliplatin when used at $100 \mu \mathrm{M}$. In addition, the number of apoptotic cells and the activation of caspase- 3 did not significantly increase when the cells were exposed to both RAD001 and oxaliplatin. This might be explained by the fact that inhibition of P70S6K by RAD001 induces IGF-IR/IRS-1/PI3K signaling, eventually increasing the level of Akt phosphorylation [22]. This feedback mechanism might be responsible for the decrease in sensitivity to oxaliplatin, leading to a reduction in the inhibition of cell proliferation. These results are consistent with the recent report that inhibition of mTOR resulted in Akt activation in several human cancer cell lines [22].

In summary, this study presents the possible mechanism in oxaliplatin resistance in cholangiocarcinoma cells. As proof-of-concept, we are able to show that activation of the Akt signaling pathway has a potent effect on oxaliplatin resistance. The model presented here may serve as a practical tool for identifying the molecular mechanism of chemotherapeutic drug-resistance in cholangiocarcinoma cells.

\section{Abbreviations}

mTOR: Mammalian target of rapamycin; PI3-K: Phosphatidylinositol-3 kinase; TUNEL: Terminal deoxynucleotidyl transferase.

\section{Competing interests}

The authors declare that they have no competing interests.

\section{Authors' contributions}

KL conceived of the study, designed, coordinated the study, statistical analysis and drafted the manuscript, SN carried out the proliferation and western blotting assays and helped with the statistical analysis, WU carried out the TUNEL and western blotting assays, SL revised the manuscript critically for important intellectual content, and helped draft the manuscript, ST also gave final approval for the paper to be submitted for publication.

\section{Acknowledgements}

This study was partly funded by Thailand Research Fund, Rajavithi Hospital and Chulabhorn Cancer Center.

\section{References}

I. Sano T, Shimada K, Sakamoto Y, Yamamoto J, Yamasaki S, Kosuge T: One hundred two consecutive hepatobiliary resections for perihilar cholangiocarcinoma with zero mortality. Ann Surg 2006, 244(2):240-247.

2. Yang W-L, Zhang X-C, Zhang D-W, Tong B-F: Diagnosis and surgical treatment of hepatic hilar cholangiocarcinoma. Hepatobiliary Pancreat Dis Int 2007, 6(6):63I-635.

3. Jordan K, Kellner O, Kegel T, Schmoll H-J, Grothey A: Phase II trial of capecitabine/irinotecan and capecitabine/oxaliplatin in advanced gastrointestinal cancers. Clin Colorectal Cancer 2004, 4(1):46-50.

4. Woynarowski JM, Faivre S, Herzig MC, Arnett B, Chapman WG Trevino AV, Raymond E, Chaney SG, Vaisman A, Varchenko M, Juniewicz PE: Oxaliplatininduced damage of cellular DNA. Mol Pharmacol 2000, 58(5):920-927.

5. Androulakis N, Aravantinos G, Syrigos K, Polyzos A, Ziras N, Tselepatiotis E, Samonis G, Kentepozidis N, Giassas S, Vamvakas L, Georgoulias V: Oxaliplatin as first-line treatment in inoperable biliary tract carcinoma: a multicenter phase II study. Oncology 2006, 70(4):280-284.

6. Zhang CX, Huang S, Xu N, Fang JW, Shen P, Bao YH, Mou BH, Sh MG, Zhong XL, Xiong PJ: Phase II study of epirubicin plus oxaliplatin and infusional 5- fluorouracil as first-line combination therapy in patients with metastatic or advanced gastric cancer. Anticancer Drugs 2007, 18(5):58I-586.

7. Nehls O, Oettle H, Hartmann JT, Hofheinz RD, Hass HG, Horger MS, Koppenhöfer U, Hochhaus A, Stieler J, Trojan J, Gregor M, Klump B: Capecitabine plus oxaliplatin as first-line treatment in patients with advanced biliary system adenocarcinoma: a prospective multicentre phase II trial. $\mathrm{Br} J$ Cancer 2008, 98(2):309-3।5.

8. Leelawat K, Leelawat S, Narong S, Hongeng S: Roles of the MEKI/ 2 and AKT pathways in CXCLI 2/CXCR4 induced cholangiocarcinoma cell invasion. World J Gastroenterol 2007, I3(I0): $156 \mid-1568$.

9. Lee S, Choi E-J, Jin C, Kim D-H: Activation of PI3K/Akt pathway by PTEN reduction and PIK3CA mRNA amplification contributes to cisplatin resistance in an ovarian cancer cell line. Gynecol Oncol 2005, 97(I):26-34.

10. Kim S, Lee T-J, Park J-W, Kwon TK: Overexpression of cFLIPs inhibits oxaliplatin-mediated apoptosis through enhanced XIAP stability and Akt activation in human renal cancer cells. J Cell Biochem 2008, 105(4):97I-979.

II. Gera JF, Mellinghoff IK, Shi Y, Rettig MB, Tran C, Hsu JH, Sawyers CL, Lichtenstein AK: AKT activity determines sensitivity to mammalian target of rapamycin (mTOR) inhibitors by regulating cyclin DI and c-myc expression. J Biol Chem 2004, 279(4):2737-2746.

12. Troiani T, Lockerbie O, Morrow M, Ciardiello F, Eckhardt SG Sequence-dependent inhibition of human colon cancer cell growth and of prosurvival pathways by oxaliplatin in combination with ZD6474 (Zactima), an inhibitor of VEGFR and EGFR tyrosine kinases. Mol Cancer Ther 2006, 5(7): | 883-|894.

13. Patel T, Singh P: Cholangiocarcinoma: emerging approaches to a challenging cancer. Curr Opin Gastroenterol 2007, 23(3):3 I 7-323.

14. Bidoli $P$, Zilembo N, Cortinovis D, Mariani L, Isa L, Aitini E, Cullurà D, Pari F, Nova P, Mancin M, Formisano B, Bajetta E: Randomized phase II three-arm trial with three platinum-based doublets in metastatic non-small-cell lung cancer. An Italian Trials in Medical Oncology study. Ann Oncol 2007, 18(3):46I-467.

15. Tsurutani J, West KA, Sayyah J, Gills J], Dennis PA: Inhibition of the phosphatidylinositol 3-kinase/Akt/mammalian target of rapamycin pathway but not the MEK/ERK pathway attenuates laminin-mediated small cell lung cancer cellular survival and resistance to imatinib mesylate or chemotherapy. Cancer Res 2005, 65(18):8423-8432.

16. Meynard D, Le Morvan V, Bonnet J, Robert J: Functional analysis of the gene expression profiles of colorectal cancer cell lines in relation to oxaliplatin and cisplatin cytotoxicity. Oncol Rep 2007, 17(5):1213-1221.

17. Ueki K, Yamamoto-Honda R, Kaburagi Y, Yamauchi T, Tobe K, Burgering BM, Coffer PJ, Komuro I, Akanuma Y, Yazaki Y, Kadowaki T: Potential role of protein kinase B in insulin-induced glucose 
transport, glycogen synthesis, and protein synthesis. J Biol Chem 1998, 273(9):5315-5322.

18. Fasolo A, Sessa C: $\mathbf{m}$ TOR inhibitors in the treatment of cancer. Expert Opin Investig Drugs 2008, I7( I I): 17 I7-1734.

19. Tanaka C, O'Reilly T, Kovarik JM, Shand N, Hazell K, Judson I, Raymond E, Zumstein-Mecker S, Stephan C, Boulay A, Hattenberger M, Thomas G, Lane HA: Identifying optimal biologic doses of everolimus (RADOOI) in patients with cancer based on the modeling of preclinical and clinical pharmacokinetic and pharmacodynamic data. J Clin Oncol 2008, 26( (10):1596-1602.

20. Beuvink I, Boulay A, Fumagalli S, Zilbermann F, Ruetz S, O'Reilly T, Natt F, Hall J, Lane HA, Thomas G: The mTOR inhibitor RAD00 I sensitizes tumor cells to DNA-damaged induced apoptosis through inhibition of p2I translation. Cell 2005, I 20(6):747-759.

21. Mabuchi S, Altomare DA, Cheung M, Zhang L, Poulikakos PI, Hensley $\mathrm{HH}$, Schilder RJ, Ozols RF, Testa JR: RAD00I inhibits human ovarian cancer cell proliferation, enhances cisplatin-induced apoptosis, and prolongs survival in an ovarian cancer model. Clin Cancer Res 2007, I3(14):426I-4270.

22. O'Reilly KE, Rojo F, She QB, Solit D, Mills GB, Smith D, Lane H, Hofmann F, Hicklin DJ, Ludwig DL, Baselga J, Rosen N: mTOR inhibition induces upstream receptor tyrosine kinase signaling and activates Akt. Cancer Res 2006, 66(3): I500-I508.

Publish with Bio Med Central and every scientist can read your work free of charge

"BioMed Central will be the most significant development for disseminating the results of biomedical research in our lifetime. "

Sir Paul Nurse, Cancer Research UK

Your research papers will be:

- available free of charge to the entire biomedical community

- peer reviewed and published immediately upon acceptance

- cited in PubMed and archived on PubMed Central

- yours - you keep the copyright

Submit your manuscript here:

http://www.biomedcentral.com/info/publishing_adv.asp
BioMedcentral 